\title{
Live Specimens More Effective than World Wide Web for Learning Plant Material
}

\author{
Roman Taraban,* Cynthia McKenney, Ellen Peffley, and Ashley Applegarth
}

\begin{abstract}
The World Wide Web and other computer-based media are new teaching resources for plant identification. The purpose of the experiments reported here was to test whether learning plant identification for woody and herbaceous plant material over the web was as effective, more effective, or preferred by undergraduate students when compared with instruction in the greenhouse. Students were exposed to web and greenhouse instruction (Exp. 1, $N=47$; Exp. 2, $N=225$ ) or they were randomly assigned to web or greenhouse learning conditions (Exp. 2, $N=225$; Exp. $3, N=224)$. The dependent measure was accuracy on identification tests of live specimens in the greenhouse. In each case, mean scores of participants receiving live instruction were significantly higher than those receiving web instruction. Questionnaire data revealed that students preferred live instruction over web instruction, that students perceived live instruction as superior to web instruction, that they preferred to learn new plant material in the classroom rather than on the web, and that web learning was frustrating. The findings indicate that web instruction is not in general superior to live instruction for plant identification, when students are required to use web instruction.
\end{abstract}

A SIGNIFICANT PART OF WHAT STUDENTS LEARN in horticulture and plant science classes is the identification of plants. This includes the common and Latin names for plants; the terminology for leaf shapes, margins, and bases; and cone and flower characteristics (Shaw, 1993). When computerbased media and methods for instruction became available, there were many reasons for adopting those applications. Indoor specimens take up space and require attention (Kahtz, 2000). In an ideal world, live plant specimens would always be available, but in reality, that is not the case. Plants vary with the seasons, and seasonal variations cannot be seen at one time when using live specimens (Kling et al., 1996). Field experiences depend on fair weather. Even the best reference books exclude a lot of important visual information (Kling et al., 1996). The World Wide Web (henceforth, the web) and other large-capacity media, like CD-ROM disks, provide speed and ease of access, and a vast array of searchable information (Sutherland, 1998). The web and computer media eliminate the need to maintain plant specimens or to distribute information in a printed form, and make aggregating and updating information easy for the instructor. Large-scale efforts have

R. Taraban, Dep. of Psychology, Texas Tech Univ., Lubbock, TX 79409-2051; C. McKenney, Texas A\&M Research \& Extension Center Dallas, Texas A\&M Univ., 17360 Coit Road, Dallas, TX 75252-6599; E. Peffley, Plant and Soil Science, Texas Tech Univ., Lubbock, TX 79409; and A. Applegarth, Lubbock, TX. Received 5 May 2003. *Corresponding author (roman.taraban@ttu.edu).

Published in J. Nat. Resour. Life Sci. Educ. 33:106-110 (2004) http://www.JNRLSE.org

(C) American Society of Agronomy

677 S. Segoe Rd., Madison, WI 53711 USA produced databases like HortBase (Kjelgren and Rupp, 1998) and UIPLANTS (Kling et al., 1996).

The availability of powerful graphics tools and web authoring and technology tools has led more instructors to tailor multimedia instructional materials and activities to the needs of their students (Bassett, 1998). Web and CD-ROM materials provide students with 24-hour access to information and allow them to work at their own pace. Pedagogically, webbased instruction is thought to promote active rather than passive learning (Sheppard, 2002). Only recently have instructors begun assessing the effectiveness of computer-based instruction compared with traditional field instruction.

In a typical 2- to 3-hour field lab for plant identification, students are introduced to about a dozen new species. The lab might include outdoor experiences as well as specimens in an indoor laboratory and commentary by the instructor. Seiler et al. (1997) developed materials for woody plant identification in a dendrology course that allowed students to learn terminology through computer-delivered self-paced learning. Fiftyfive percent of the enrolled students used the program. Overall, students reported that the program was easy to use, useful, and they liked it. However, the students thought the program should be used as a supplementary aid and should not replace field instruction. In two additional studies involving students enrolled in dendrology, Seiler et al. (2002) tested whether optional computer-based instruction transferred to field identification. Field scores of students who used the instructional software showed an $8 \%$ gain compared with nonusers, who showed only a $1 \%$ gain, relative to baseline scores. The most surprising finding was that few students chose to use the software at all (10 users vs. 81 nonusers). In a second study, Seiler et al. (2002) matched users to nonusers while controlling for grade point averages (GPAs) and compared final course grades. Users had higher final grades $(80.8 \%)$ than nonusers $(75.9 \%)$. Both findings suggested that students who self-selected to use computer instruction as a supplementary aid benefited from the additional resource.

Kahtz (2000) randomly assigned students in woody plant identification classes to one of two groups. The treatment group had access to a plant identification program called UIPLANTS (Kling et al., 1996) as a supplement to traditional instruction. In two separate semesters, there were no significant differences between treatment and control groups in plant identification quiz scores.

In two studies, computer instruction was compared with classroom instruction. Rieger (2002) reported that in two semesters those students who elected to take a distance education (DE) version of the course Introduction to Fruit Crops did significantly better on proctored comprehensive final examinations compared with classroom students. However, in a

Abbreviations: ANOVA, analysis of variance; DE, distance education; GPA, grade point average; SR-ASHS, Southern Region-American Society of Horticultural Science. 
third test, classroom performance exceeded DE performance, although the advantage was not significant. Jeannette and Meyer (2002) compared an online version of a master gardener course to traditional classroom delivery and found no significant differences between classroom and online groups on pretests and posttests, although caution must be exercised in interpreting the results because the online students' posttests were not proctored. At the end of the course, online students favored distance learning and indicated that they would take another web course.

In the studies in which computer materials were supplemental to traditional instruction with live specimens, students used the materials by choice. In other studies, students selected computer-based instruction. Evaluation of the software by users was biased by this factor of self-selection, and thereby poses a limitation to the generality of the findings. In the experiments reported here, the effects of self-selection were minimized through the random assignment of students to the web and traditional greenhouse instructional methods. Because there are many real-life circumstances in which students cannot self-select their mode of instruction (e.g., if a course is only offered over the web, or if a web course is the only form available to off-campus students), it was important to assess the efficacy of computer-based offerings when self-selection was not a factor.

Students study plant material to identify living specimens, not images on a computer; thus, the dependent measure in the present studies was live plant identification. In each experiment the effectiveness of web instruction was compared with traditional instruction in the greenhouse. One hypothesis was that web instruction would be as effective as or more effective than instruction in the greenhouse, and another was that students would prefer web instruction over live instruction. Both hypotheses were based on the presumed advantages afforded by ease of access and self-paced learning when instruction takes place over the web.

\section{MATERIALS AND METHODS}

\section{Overview}

Three experiments were conducted using undergraduate students enrolled in Principles of Horticulture, an introductory course in plant science that included laboratory sections. Participants learned to identify herbaceous and woody plants in a traditional laboratory section, through web instruction, or both. The traditional laboratory instruction for herbaceous material took place in the greenhouse, and for woody material through a campus tour. Instructors presented live plant examples and participants had an opportunity to examine and study live plants. In the web method, participants viewed text and images of the plants over the web. The information provided to each lab section was scripted, and handouts and practice materials were identical in the live and web sections. To test knowledge of the material, students were required to provide the common and scientific names of live woody and herbaceous plants. Test score was the performance measure.

To test the hypothesis that participants would prefer the web to traditional instruction, they also completed summative questionnaires that were used to evaluate their perceptions of traditional laboratory instruction vs. web instruction for plant identification, their study behaviors, and their computer backgrounds. Participants were asked whether they enjoyed web or traditional learning, whether web or live instruction was superior, and whether they would prefer to learn plant identification in the classroom or on the web. Because web instruction may have been new for students, the questionnaire also included questions about ease of access and use of Internet connections, and adequacy of technical support. Participants were asked how much anxiety and frustration they may have felt while learning by either method.

There were minor adjustments in the web materials, procedures, and items on the questionnaire across the three replications, but none that changed the substance of the experimental questions. Because the quality of web materials is an important consideration, we note that the website for woody and herbaceous plants won a blue ribbon from the Southern Region-American Society of Horticultural Science (SRASHS). To view the website, go to www.pssc.ttu.edu/techhort (verified 2 July 2004).

\section{Experiment 1}

Participants were drawn from the Principles of Horticulture course during the spring term. For the course overall, $46 \%$ of students were males and $54 \%$ were females, the median age was 19.6 years, $52 \%$ of the students were freshman, $34 \%$ were sophomores, and the remainder were juniors or seniors. Only $15 \%$ of the students were horticulture or agriculture-related majors, with the remainder representing 37 distinct majors. The ethnic distribution was $91 \%$ Caucasian, $6 \%$ Hispanic, $2 \%$ African-American, and less than $1 \%$ each of Asian and American Indian students. The 47 students who participated in this experiment were enrolled in one of several sections of the course. Their mean GPA was $2.79 \pm 0.83 \mathrm{SD}$ on a 4-point scale $(4=\mathrm{A})$.

The primary materials were live specimens of 12 woody and 13 herbaceous plants and images of these plants that were delivered over the web. A handout to all participants described the general characteristics and cultures of the plants and their life cycle habit (e.g., annuals, perennials). Web participants received information on accessing the website. Two worksheets were used - a paper worksheet for traditional lab instruction and an electronic worksheet for web instruction-and provided participants with practice in identification.

During a preliminary meeting, participants were randomly assigned to either live instruction in the greenhouse or web instruction for the herbaceous plants, and subsequently received the converse form of instruction for the woody lab. Participants receiving live instruction for herbaceous plants were given a greenhouse tour by the instructor, and could return to the greenhouse during regular daytime hours, Monday through Friday. Those students receiving live instruction for woody plants were taken on a walking tour around campus. Web instruction participants were given directions for accessing a password-protected website. During live instruction, the instructor answered student questions face to face, while questions from web instruction students were answered through email. Participants from either treatment group took a test in the greenhouse that required them to identify and provide the common and scientific names for the 12 woody plants and 13 herbaceous plants that were the focus of their studies. 
Table 1. Average test performance ( \pm SD) for Exp. 1 to 3, reported as proportion correct.

\begin{tabular}{lccc}
\hline Condition & Exp. 1 & Exp. 2 & Exp. 3 \\
\hline Live & $0.80(0.20) \mathrm{a}^{*}$ & $0.84(0.19) \mathrm{a}$ & $0.81(0.24) \mathrm{a}$ \\
Web & $0.73(0.24) \mathrm{b}$ & $0.77(0.18) \mathrm{b}$ & $0.64(0.25) \mathrm{b}$ \\
Web supplement & -- & $0.76(0.20) \mathrm{b}$ & -- \\
\hline
\end{tabular}

* Within columns, means followed by different letters are significantly different, at least at the 0.05 probability level. See the text for details of the tests.

\section{Experiment 2}

A total of 312 students enrolled in the course Principles of Horticulture during the subsequent fall term. Demographic data were nearly identical to those of Exp. 1, except that a higher proportion of participants $(27 \%)$ were horticulture or agriculture-related majors. Students were assigned by lab section to one of three experimental groups: live instruction, web instruction, or live instruction with optional web access. Only those students who completed the test and questionnaire were used in the analyses: 61 participants in the live instruction group, 87 in the web group, and 77 in the web supplement group ( $72 \%$ of the enrolled students). The primary materials were specimens and images of 25 woody plants and 25 herbaceous plants. In all other respects, the materials and test were the same as those used in Exp. 1. There was one important addition to the procedure: participants in the web group and the web supplement group met in a computer classroom for an orientation meeting before beginning web instruction. Participants in the web supplement group met in the greenhouse, like the participants in the live instruction group.

\section{Experiment 3}

There were 224 students enrolled in 1 of 13 sections of the Principles of Horticulture class, who were randomly assigned by section to live instruction or web instruction. Student profiles were similar to the first two experiments. The primary materials were specimens and images of 25 woody plants. In all other respects, this experiment was similar to Exp. 1 and 2.

\section{Statistical Methods}

Test score data were analyzed using $t$ tests and analysis of variance (ANOVA). Nearly all questionnaire responses were made using five-point Likert-type ratings. Nonparametric statistical methods were applied to the questionnaire data because response intervals could not be assumed to be equal, and because of possible nonnormal response distributions. Analyses of the questionnaire data presented in this paper were carried out using sign tests, which is appropriate for comparing ranked responses from two related samples (SPSS Inc., 1990; Conover, 1999).

\section{RESULTS}

\section{Student Performance}

Student performance on tests and statistical differences between groups are summarized in Table 1. Performance was significantly higher in the live instruction group compared with the web group in all three experiments. In Exp. 1, a paired $t$ test showed a significant difference between instruction groups $[t(46)=2.11, p<0.05]$. In Exp. 2, a one-way ANOVA indi- cated significant differences between instruction groups $[F(2$, $222)=3.74, p<0.03]$ and the Tukey HSD (honestly significant differences) test ( $\alpha=0.05)$ was used to test for pairwise differences between groups. In Exp. 3, a 2 (instruction group: live, web) $\times 13$ (course section) ANOVA indicated significant differences between instruction groups $[F(1,198)=26.97, p$ $<0.001]$ and between course sections $[F(12,198)=2.02, p$ $<0.03]$, but not for the interaction of the two factors $[F(12$, $198)=1.44, \mathrm{NS}]$. In all but one section mean test performance was higher for the live vs. web group. Overall, when students studied live specimens they did better on plant identification and naming than when they studied the plant images on the web.

Additional data were consistent with the live instruction advantage. In Exp. 3, test scores were positively correlated with self-reported GPA for participants in the live instruction $(r=$ $0.40)$ and web instruction $(r=0.27)$ groups; the significant test advantage for the live instruction group remained even after adjusting for GPA $[F(1,193)=25.68, p<0.001]$. An examination of self-reported study times for Exp. 3 showed that participants in the live instruction group reported mean times of 104 minutes $(\mathrm{SD} \pm 77.3)$ in response to the question, "How much time did you spend studying the plant material for the Woody Plant ID Quiz (not including the time you spent as a group going over the plant material with your lab demonstrator)?" Participants in the web group reported mean study times of 196 minutes (SD \pm 136.2$)$, including a mean of 139 minutes $(\mathrm{SD} \pm 117.3)$ at the computer and 57 minutes $(\mathrm{SD} \pm$ 62.0) away from the computer. Many students studied only at the computer; thus, this latter distribution was positively skewed. These data did not suggest that the advantage for live instruction was due to significantly longer study times.

\section{Participants' Reactions to Greenhouse and Web Instruction}

Responses to questionnaires that were distributed to participants in all three experiments did not support the hypothesis that students would prefer the web to traditional instruction. Participants enjoyed classroom learning over web learning, they asserted that classroom instruction was superior to web instruction, and they preferred to learn new material in the classroom rather than on the computer. These outcomes were most likely not due to participants' lack of experience with computers and the web, based on the questionnaire data in the two experiments in which this possibility was probed: in Exp. 1, all but one participant indicated previous experience with computers and $89 \%(n=42)$ indicated experience with the web; in Exp. 2, all but six participants indicated previous experience with computers and $92 \%(n=209)$ had web experience. Participants in both experiments generally indicated that technical support was accessible.

For the sake of simplicity, detailed analyses of questionnaire responses are presented only for Exp. 1. Outcomes for the other two experiments were very similar. Table 2 summarizes participants' responses organized into five pairs of contrasting statements. Participants enjoyed learning about plants in the greenhouse more than learning about them on the web $(Z=5.40, p<0.0001)$, they preferred learning by live instruction rather than web instruction $(Z=6.02, p<0.0001)$, and they preferred learning new plant material in the class- 
room, not on the web $(Z=5.93, p<0.0001)$. Their anxiety about learning plant material in general did not differ from their anxiety about learning it on a computer $(Z=0.34, \mathrm{NS})$. However, their frustration in learning to identify plant material in general was significantly less than their frustration in using a computer to learn plant material $(Z=4.73, p<0.001)$.

\section{DISCUSSION}

Plant identification is highly visual and is usually taught as a hands-on activity through field experiences and through the examination of live specimens. Students must learn to identify subtle features of plants and are expected to be able to identify plants at different times of the year (Kahtz, 2000). Live specimens are not always available, and at any given time of year do not exemplify the variation of the plant across the seasons. Teaching via the web and through other emerging computer technologies is a relatively new possibility for instruction and learning. The three experiments reported here provided consistent and reliable evidence against the hypothesis that students would do as well or better using web materials compared with live instruction. In other research that addressed similar questions, Wang and Newlin (2000) reported that students enrolled in traditional sections of psychological statistics earned higher grades on the final exams and received higher course grades than students who completed the course in a web-based format, further indicating that webbased instruction is not necessarily superior to traditional methods.

The present findings do not negate the value of web instruction. In the present experiments, web students' average performance on plant identification tests was in the range of 64 to $77 \%$. Students were able to learn from the web in these studies and in others. For example, Seiler et al. (2002) showed that students successfully learned to identify live woody specimens using computer tutorials. The web is particularly useful for allowing access to difficult-to-obtain materials. Sheppard (2002) developed web-based modules for teaching dendrochronology, which involves tasks for which students do not easily acquire source materials. The web made the necessary materials readily accessible and instruction focused on concepts instead of on time-consuming library searches and the acquisition of relevant materials. Comprehension test scores indicated substantial learning.

Our results support a conclusion from Phipps and Merisotis (1999), who indicated that "the higher education community has a lot to learn regarding how, and in what ways, technology can enhance the teaching/learning process, particularly at a distance." Anderson and Walker (2003) indicated that live instruction may be more effective because limited access to the plant material motivates students to generate detailed notes about plant differences. If Anderson and Walker are correct, then there might be reason to qualify Sheppard's (2002) suggestion that the web promotes active learning. As much, or more, active learning could take place in the traditional lab. Given the complexity of the classroom, the most effective approach to the development of web-based materials that promote learning and student satisfaction may require a multifaceted approach. This approach should examine students' interactions with the web materials within the larger context of other course activities such as lectures, the number and kinds
Table 2. Mean ( \pm SD) and median Likert ratings $\dagger$ for Exp. 1 questionnaire responses.

\begin{tabular}{|c|c|c|}
\hline Contrasts & Mean $( \pm \mathrm{SD})$ & Median \\
\hline \multicolumn{3}{|l|}{ Enjoyment (1: not much, 5: very much) } \\
\hline $\begin{array}{l}\text { How much did you enjoy learning plant material } \\
\text { in the classroom? }\end{array}$ & $3.96(0.86)$ & 4.00 \\
\hline $\begin{array}{l}\text { How much did you enjoy learning plant material } \\
\text { on the computer? }\end{array}$ & $2.21(1.21)$ & 2.00 \\
\hline \multicolumn{3}{|l|}{ Effectiveness (1: no, $5:$ yes $)$} \\
\hline $\begin{array}{l}\text { Did the plant material and verbal descriptions in class } \\
\text { allow for identification of live plant material? }\end{array}$ & $4.57(0.71)$ & 5.00 \\
\hline $\begin{array}{l}\text { Did the pictures and written descriptions on the computer } \\
\text { allow for identification of live plant material? }\end{array}$ & $2.45(1.06)$ & 2.00 \\
\hline \multicolumn{3}{|l|}{ Preference (1: no, 5: yes) } \\
\hline $\begin{array}{l}\text { Given a choice, would you use the classroom to learn } \\
\text { new plant material? }\end{array}$ & $4.72(0.65)$ & 5.00 \\
\hline $\begin{array}{l}\text { Given a choice, would you use a web site to learn } \\
\text { new plant material? }\end{array}$ & $1.70(1.21)$ & 1.00 \\
\hline \multicolumn{3}{|l|}{ Anxiety (1: not anxious, 5 : very anxious) } \\
\hline $\begin{array}{l}\text { What was your anxiety level about learning to identify } \\
\text { plant material? }\end{array}$ & $3.06(1.11)$ & 3.00 \\
\hline $\begin{array}{l}\text { What was your anxiety level about using the computer } \\
\text { to learn plant material? }\end{array}$ & $3.09(1.40)$ & 3.00 \\
\hline \multicolumn{3}{|l|}{ Frustration (1: not frustrated, $5:$ very frustrated) } \\
\hline $\begin{array}{l}\text { What was your frustration level about learning to identify } \\
\text { plant material? }\end{array}$ & $2.89(1.05)$ & 3.00 \\
\hline $\begin{array}{l}\text { What was your frustration level about using the computer } \\
\text { to learn plant material? }\end{array}$ & $4.13(1.15)$ & 5.00 \\
\hline
\end{tabular}

of assigned homework problems, student incentives, and other student resources (Anderson et al., in press).

\section{ACKNOWLEDGMENT}

These studies were funded in part by USDA Challenge Grant no. 97039842 to Ellen Peffley and Cynthia McKenney. Ashley Applegarth completed Exp. 1 and 2 in partial fulfillment of the requirements to earn a Master's degree.

\section{REFERENCES}

Anderson, E.E., R. Taraban, and M.P. Sharma. Implementing and assessing computer-based active learning materials in introductory thermodynamics [Online]. Interactive version available at www.ijee.dit.ie/OnlinePapers/Interactive_Papers.html (accessed 10 Dec. 2003; verified 8 July 2004). Int. J. Eng. Educ. (in press).

Anderson, N.O., and J.D. Walker. 2003. Effectiveness of web-based versus live plant identification tests. HortTechnology 13:199-205.

Bassett, C. 1998. Applying computer technology to horticulture education and research. HortTechnology 8:18-19.

Conover, W.J. 1999. Practical nonparametric statistics. 3rd ed. John Wiley, New York.

Jeannette, K.J., and M.H. Meyer. 2002. Online learning equals traditional classroom training for master gardeners. HortTechnology 12:148-156.

Kahtz, A.W. 2000. Can computer-assisted instruction be used by students for woody plant identification? HortTechnology 10:381-384.

Kjelgren, R., and L. Rupp. 1998. Using HortBase in education. HortTechnology 8:301-306.

Kling, G.J., C.P. Lindsey, and M.E. Zampardo. 1996. UIPLANTS: A software program for landscape industry and horticulture education. HortTechnology 6:337-343.

Phipps, R., and J. Merisotis. 1999. What's the difference? A review of contemporary research on the effectiveness of distance learning in higher education [Online]. Available at www.ihep.com (accessed 28 Dec. 2003; verified 2 July 2004). The Institute for Higher Education Policy, Washington, DC.

Rieger, M. 2002. Distance education versus classroom instruction in horticulture: An introduction to fruit crops: Case study. HortTechnology 12:513-515.

Seiler, J.R., J.A. Peterson, C.D. Taylor, and P.P. Feret. 1997. A computer-based multimedia instruction program for woody plant identification. J. Nat. Resour. Life Sci. Educ. 26:129-131.

J. Nat. Resour. Life Sci. Educ., Vol. 33, 2004

- 109 
Seiler, J.R., O. Popescu, and J.A. Peterson. 2002. A woody plant identification tutorial improves field identification skills. J. Nat. Resour. Life Sci. Educ. 31:12-15.

Shaw, P.M. 1993. A low-cost interactive computer program for teaching landscape plant materials. HortTechnology 3:351-354.

Sheppard, P.R. 2002. Web-based tools for teaching dendrochronology. J. Nat. Resour. Life Sci. Educ. 31:123-130.

SPSS Inc. 1990. SPSS reference guide. SPSS, Chicago, IL

Sutherland, A. 1998. Introduction to the colloquium: Today's information resource. HortTechnology 8:290-291.

Wang, A.Y., and M. H. Newlin. 2000. Characteristics of students who enroll and succeed in psychology web-based classes. J. Educ. Psychol. 92:137-143. 